\title{
THE BACKYARD POLITICS OF ATTITUDES TOWARDS IMMIGRATION
}

Over the past fifty years, immigration has become an issue of particular salience in the U.S. The growing number of foreign-born residents is no longer neatly concentrated in select regional pockets, but permeates communities throughout the nation (Frey, 2006; Wilson \& Svajlenka, 2014). Reactions to these immigration trends have been exceptionally inconsistent. While a majority of Americans believe that most immigrants cause problems for the country and want to keep them out, large and stable majorities also feel that immigrants are hard working, honest, and that they enrich the United States with their cultures and talents (Lapinski et al., 1997; Pew Research Center, 2006). Americans seem to see immigrants as both the source of societal problems as well as societal enrichment; as destructive people whom they want to keep out of the country, and as a valuable addition to the nation in which they live (Schildkraut, 2011).

A prominent set of explanations for these seeming inconsistencies has focused on the attributes of immigrants who are salient or "top-of-the-head" - especially those depicted in the media (Branton et al., 2011; Zaller and Feldman, 1992). In particular, indicators of a salient immigrant's assimilation to mainstream American cultural norms have repeatedly demonstrated pronounced effects on immigration attitudes (Schildkraut, 2005; Branton et al., 2011; Wright et al., 2015). Yet in contrast to its effect on attitudes toward many other policy issues disproportionately affecting non-whites, the racialized physical traits of salient beneficiaries and particularly Afrocentric physical traits ${ }^{1}$ - have failed to demonstrate a clear relationship with

\footnotetext{
${ }^{1}$ In this study I use the term "racialized physical traits" to refer to what Iyengar et al. (2013) labeled Afrocentric attributes, or the "presence of facial features representative of Black Africans, most notably a darker complexion, fuller lips, and a wider nose." There is in line with evidence that "skin tone is not the sole index of color identifications. Facial features, such as shape of one's nose, eyes, and lips, also contribute to perceptions of a person's color, as does the texture and style of one's hair', (Harris, 2008, p. 60). While there are many other traits that have been racialized, these traits have an especially well-documented history of being used to divide individuals
}

This is the author manuscript accepted for publication and has undergone full peer review but has not been through the copyediting, typesetting, pagination and proofreading process, which may lead to differences between this version and the Version record. Please cite this article as doi:10.1111/ pops.12314. 
immigration attitudes (Harell et al., 2012; Hopkins, 2014; Iyengar et al., 2013). In turn, some have read this as evidence that opposition to immigration is heavily influenced by cultural concerns, and surprisingly unaffected by the racialized physical traits of salient immigrants. In this paper, I reconsider the role of both assimilation and racialized physical traits in shaping immigration attitudes in light of evidence that these attributes tend to raise concerns in different contexts. In the United States today, there is a widespread and outspoken movement seeking to reinforce a shared national culture, with a single language and set of values (Huntington, 2004; Schildkraut 2005; Grovum, 2014). Underlying these views is a perspective that matters of culture and assimilation are not solely of individual or local relevance, but diffuse issues of broad significance. In contrast, concerns about race are not as salient in the context of national issues, or ones considered in the abstract. In fact, views on racial integration and other policies with majority non-white beneficiaries are often comparatively liberal when considered in a broad, national context. It is when they are considered in a personal or local context that the racial undertones of "deserving" and "undeserving" become more pronounced (Bobo, 2011; Schuman et al., 1997). Thus, I explore the role of a salient immigrant's racialized physical traits and level of assimilation in attitudes toward immigration in light of this difference. I hypothesize that exposure to immigrants perceived to be unassimilated will heighten restrictive attitudes towards immigration when considered in both national and socially proximate contexts. Bias against immigrants with Afrocentric physical traits, however, will be most clear when the issue of immigrations is framed in a personally relevant context. In doing so, I ask whether attitudes

perceived to be of principally European ancestry from those perceived to be principally of non-European ancestry, in order to reinforce a legal, economic and social stratification system in the U.S. (Allen 1997; Haney-Lopez 2006; Weaver, 2012). Furthermore, psychological research provides evidence that White (and non-white) subjects spontaneously judge faces according to the degree to which they display these traits (Golby et al. 2001; Blair et al., 2002). 
toward immigration are really race-blind, or whether this "blindness" is simply conditional on the immigrants not affecting the racial landscape of respondents' everyday lives?

\section{RACIALIZED TRAITS, CULTURE AND ATTITUDES TOWARD IMMIGRATION}

Throughout U.S. history, race has played a powerful role in shaping political attitudes (Myrdal, 1944; Kinder \& Sanders, 1996; Kuklinski et al., 1997; Hutchings \& Valentino, 2004; Weaver, 2012). Racial attitudes have not only been associated with opinions on explicitly racial issues, such as busing and affirmative action, but also with others issues that are only implicitly racialized, such as welfare spending and tax increases (Valentino, Hutchings \& White, 2002;

Sears et al., 1997; Gilens, 1995). Consistent with this, many surveys show that there is generally less support for immigration from those who look different from a majority of white Americans, that is, those with darker skin and less European features (Citrin \& Green, 1997; Burns \& Gimpel, 2000; Brader et al., 2008). These patterns are consistent with the association between racial resentment and opinion on matters of immigration. Those who resent blacks are more likely to favor restrictions on the flow of immigrants into the country, more likely to say that those who do come into the country should not be eligible for government benefits, and more likely to fayor the establishment of English as an official language (Kinder \& Sanders, 1996). In turn, there is good reason to expect that the racialized physical traits of salient immigrants are playing an important role in how people understand and think about immigration policies.

Yet despite the theoretical support and correlational evidence, there is surprisingly little proof of direct relationships between attitudes towards immigration and the racialized features of salient immigrants. Experimental surveys that varied these features of salient immigrants (apart from the ethnic or national origin cues) indicated that these characteristics of an immigrant actually had no effect on American attitudes towards immigration policy (Hopkins, 2014; 
Iyengar et al., 2013) or support for the individual immigrant remaining in the U.S. (Harell et al., 2012; Iyengar et al., 2013). In two of these studies, however, indicators of an individual immigrant's level of assimilation into the cultural norms and traditions practiced by the majority of Americans proved to be an important indicator of attitudes (Hopkins, 2014; Iyengar et al., 2013). Those immigrants who were depicted as speaking English, for example, generated less restrictive attitudes towards immigration than those speaking other languages.

The role of cultural considerations in attitudes towards immigration is not new. Americans have cited immigrants' lack of willingness to assimilate to American cultural norms as being among their greatest objections to immigration (Schildkraut, 2011), and about half of Americans suggest that immigrants should give up their foreign ways upon coming to this country (Lapinski et al., 1997). The importance assigned to assimilation has been linked to the perception among many Americans that unassimilated immigrants - that is, immigrants who do not appear to be integrated into the cultural institutions and practices relied upon by the majority of Americans - pose a danger to the culture that they believe unifies Americans (Buchanan, 2006; Huntington, 2004, Paxton \& Mughan, 2006; Schildkraut, 2005). Along these lines, there is considerable evidence that the greater the perceived dissimilarity of immigrant groups to a nation's dominant group on linguistic, religious, and general cultural grounds, the more likely they are to be met with hostility (Citrin et al., 1997; Sniderman et al., 2004; Newman et al, 2012; Wright \& Citrin 2011; Hainmueller \& Hopkins 2014). It has consequently been argued that, "the reduction of prejudice against newcomers is seen as being essentially dependent on their assimilation into mainstream behaviors" (Portes et al., 1980, p. 202).

While the importance of culture in attitudes towards immigration seems consistent with the role that ethnocentrism has been shown to occupy in American political attitudes more 
broadly, the apparent non-role of racialized physical traits seems odd in light of the continuing role of racial biases in the United States (Pager at al., 2009; Milkman et al., 2012; Bobo, 2011; Bobo et al., 2012). In majority white societies, such as the U.S., people with Afrocentric features are frequently stereotyped (Maddox \& Gray 2002; Eberhardt et al. 2004; Dixon \& Maddox 2005) and subject to racial prejudice. Why would so many Americans, and particularly nonLatino white Americans, be comfortable letting immigrants with Afrocentric physical traits in the country if they are not comfortable hiring them or even responding to their emails? One possibility is that concerns about immigrants with racialized physical traits grow more palpable with proximity.

This idea that local frames heighten opposition towards racial minorities, and the policies that are perceived to benefit them, is supported by evidence that perceptions of threat among white respondents are heightened with proximity to those perceived to be non-white (Giles \& Hertz 1994; Glaser 1994; Huckfeldt \& Kohfeld 1989; Wright 1977). Consistent with this, Taylor (1998) draws upon national cross-sectional data spanning twenty years to illustrate consistent patterns of prejudice and opposition to race-targeted policies among whites as the percentage of black residents in a metropolitan area increases. Some of these studies attribute this to a particular form of threat, such as political threat, economic threat, or status threat. However, when looking at these studies together, it seems clear that all types of threat are closely linked to one another, and increase with proximity to those perceived to be non-white (Oliver \& Mendelberg, 2000). Kinder \& Mendelberg (1995) nicely summarize this pattern: "In the view of many whites, blacks in the neighborhood threaten property values and safe schools; blacks at church violate definitions of community; blacks at work stir up apprehensions about lost jobs and 
promotions....At the same time, distance from blacks allows whites the luxury of expressing racial tolerance" (Kinder \& Mendelberg, 1995, 404).

Yet there is evidence that physical proximity is not even necessary to ignite these concerns. Simply thinking about a stigmatized population or issue in a personal or local context can produce similar effects. Sometimes referred to as the Principle-Implementation Gap, people often feel comfortable supporting certain ideals when considered in abstract or distant contexts, but less so in familiar or local contexts. The tendency to hold more restrictive views when policies are framed as having a direct impact on a respondent or the respondent's community has been demonstrated across a range of policy contexts (Greenberg, 2012; Schuman et al., 1997; Cowan, 2003; Iglesias, 2002; Davis \& Bali, 2008). Of particular relevance to this study, attitudes toward racial equality tend to be quite favorable when discussed in the abstract or on an impersonal level, but become less supportive when discussed in a specific, local context, such as one's own neighborhood or family (Djamba \& Kiumna, 2014; Schuman et al., 1997; Bobo, 2011; Greenberg, 2012). For example, American whites are far more supportive of decreasing residential segregation, as a matter of principle, than they are of open housing laws or having black neighbors, in practice (Schuman et al., 1997.; Charles, 2006; Bobo et al., 2012). Accordingly, I expect that if respondents do have aversion to immigrants with Afrocentric physical traits, it will be most apparent when immigration is considered in a specific, local context, as opposed to a comparatively abstract, national context.

In considering this theory, it is important to also think about alternative explanations for the lack of evidence of a relationship between racialized physical attributes and attitudes toward immigration in past studies. One such explanation is simply that past studies were constrained by the fact that they relied on self-reported attitudes. Perhaps people were simply hesitant to share 
their opposition to immigration due to perceptions of pro-immigrant social norms (Janus, 2010). Should this be the case, however, it should affect attitudes toward all immigrants equally, regardless of the specific racialized or cultural attributes of the immigrants depicted. With this in mind, an obvious alternative explanation is that respondents are hesitant to express attitudes that could be perceived as racist, and consequently suppress their oppositional views when faced with immigrants that they perceive to be non-white. The plausibility of this theory, however, is limited by evidence that implicit anti-Latino immigrant bias has been shown to exert direct influence on immigration policy judgments, illustrating that those found to hold implicit biases against at least some racialized groups were quite comfortable explicitly reporting negative views on immigration (Peréz, 2010) ${ }^{2}$.

It is also worth noting some of the limitations of previous research that make this study particularly valuable. First among these is the fact that many studies have failed to carefully specify the characteristics of the immigrant(s) being considered. So, for example, some studies use "race" to refer to an immigrant's national group identity (i.e. Pakistani or Filipina), thereby confounding attitudes that may be associated with certain physical traits with those associated with a certain national group (Sanchez, 1997; Chandler \& Tsai, 2001; Short \& Magaña, 2002). For example, Mexican immigrants may elicit more opposition than Irish immigrants because of differences in their population size in the U.S. or the level of perceived cultural distinctiveness, rather than as a result of their racialized physical traits per se. This ambiguity is amplified by the fact that many of the earlier studies that consider the role of immigrant attributes on immigration attitudes also rely heavily on survey data (Chandler \& Tsai, 2001; Citrin et al., 1997). Although

\footnotetext{
2 The likelihood of activating respondent concerns about social desirability is further reduced by the fact that the questions used in past experimental studies, as well as this one, do not explicitly refer to the racialized physical attributes of the immigrants depicted.
} 
the evidence put forth in such research are suggestive, it is difficult to make a strong causal inference based on an observed correlation or significant regression coefficient.

Additionally, the bulk of research on attitudes toward immigration, including those studies that have manipulated racialized traits experimentally, has focused on either attitudes toward national immigration policy (Chandler \& Tsai, 2001; Harell et al., 2012; Iyengar et al., 2013), or the fate of immigrants considered in the abstract (Hopkins, 2014; Iyengar et al., 2013). In doing so, these studies may permit respondents to consider the issue and the immigrants at a distance, and enable respondents to offer responses that are less sensitive to racialized cues.

This research seeks to fill some of these gaps. While racialized physical traits and assimilation are not the only two factors that influence attitudes toward immigration, to be sure, past research suggests that they may be influential and, particularly in the case of racialized physical traits, merit further exploration. Thus, my summary prediction is that the racialized physical traits and level of assimilation of the immigrants that are salient will affect their opinions toward immigration, albeit in different ways. I hypothesize that consistent with prominent national discussions of the importance of a shared American cultural identity, greater assimilation to majority American cultural norms should encourage support for the immigrants in both national and local contexts. I expect that the racialized traits of the immigrants will also affect attitudes toward immigrants, but that direct effects will only be observed in contexts that are tangibly relevant to the respondent - that is, in their own communities or socially proximate contexts. 


\section{EXPERIMENT ONE: THE EFFECTS OF RACE AND ASSIMILATION}

In order to isolate the causal impact of racialized physical traits and assimilation, I use an experimental design embedded in a national population-based survey. This technique provides a powerful means of identifying causality, without the loss of generalizability that often comes from a convenience sample of respondents (Mutz, 2011). Data for this study were gathered by Knowledge Networks (now GfK) of Palo Alto, CA. A representative probability sample of 767 non-Latino white adults was interviewed between February 10 and February 17, 2009. I used a non-Latino white sample due to evidence of significant differences in individual attitudes towards immigration policy depending on the race and ethnicity of respondents (Pew Research Center, 2006). Using only non-Latino whites therefore allowed me to reduce the effect that variation in the race and ethnicity of the respondents played in how individuals responded to cues relating to immigration in this study. Respondents were interviewed via Internet, a survey mode that to date has not been shown to generate social desirability effects when asking respondents about sensitive topics such as racial attitudes (Chang \& Krosnick, 2009). The lack of a human interviewer in web-enabled surveys may reduce the social desirability pressures that have been found in both in-person and telephone surveys. Those who agreed to participate and did not already have Internet access in their home were provided with Internet service by Knowledge Networks.

Using a 2-by-2 fully-crossed factorial design, each respondent was randomly assigned to one of four conditions in which I manipulated 1) the racialized physical features of the immigrants, and 2) their level of assimilation (see online appendix 6 for balance checks). To manipulate the Race of the immigrants, respondents saw a photograph of either Light Raced or Dark Raced immigrants. Respondents in the Light Raced conditions saw an image of immigrants 
with light skin tones and stereotypically Eurocentric features, and those in the Dark Raced conditions viewed immigrants with dark-skin tones and stereotypically Afrocentric features (see online appendix 1). The number of people visible in the picture, their positions, gestures, clothing and the background remained identical. No specific country of origin was named in the story, and the photo eliminated characteristics that would prompt association with any one specific ethnic or national group.

To manipulate the immigrants' level of Assimilation, respondents were shown a vignette (along with the photograph) in which the immigrants were either characterized as Assimilated or Unassimilated. While the language spoken by individuals has been one of the most common metrics for assimilation (Citrin, 1990; Hopkins, 2011; Newman et al., 2012), there are undoubtedly other factors that feed into people's perceptions of assimilation. Food choices, religion, dress, and social integration are among the other elements of culture often considered when thinking about assimilation (Gordon, 1978). Thus, in the news story, the immigrants' level of cultural assimilation was manipulated through the inclusion of incidental details addressing what they were eating, the language spoken and their extent of social integration into an American community as opposed to their homeland. In the Unassimilated conditions, the type of food that was being eaten at lunch included spicy goat meat, and the restaurant was said to be part of an ethnic food market. These details contrasted with a classically American platter of mozzarella sticks, onion rings and buffalo wings being eaten at Roy's Diner in the Assimilated conditions. The Unassimilated conditions further specified that they were speaking in their native tongue, and that they were discussing events taking place in their native country as opposed to speaking in English and discussing the local baseball team in the Assimilated conditions (see online appendix 2 for exact text). 
In order to draw conclusions from the results, it is essential to verify that the independent variables - which I will refer to as Race and Assimilation - were successfully manipulated. Manipulation checks were included at the end of the survey, after asking about the key dependent measures. To check whether the racialized physical traits of immigrants were successfully manipulated, respondents were asked from which region they thought the immigrants depicted were most likely to have come. Respondents in the Dark Raced condition were significantly more likely to say the respondents were from Africa, Latin America or Southeast Asia than respondents in the Light Raced condition $(M=0.90, S E=0.02)$, while respondents in the Light Raced condition were more likely to say the immigrants were from Europe or Australia than respondents in the Dark Raced condition $(M=0.67, S E=0.02)$, $F(767)=63.99, \mathrm{p}=.00$ (see online appendix 4 for regional breakdown by condition $)^{3}$. Thus, Race was effectively manipulated. Assimilation levels were likewise successfully manipulated. Those in the Assimilated condition were significantly more likely to say that these immigrants had adopted American ways of life $(M=2.94, S E=0.03)$ than in the Unassimilated condition $(M=2.50$, $\mathrm{SE}=0.03) F(759)=87.16, \mathrm{p}=.00$ (see online appendix 5 for breakdown by treatment).

To assess opinions toward immigration policy, a series of three questions was asked. These included: 1) whether immigration helps or hurts America, 2) whether the number of immigrants in this country should be increased, decreased or kept about the same, and 3) whether the respondent favors or opposes a border fence between the US and Mexico. These three items were combined into an overall index of Immigration Policy Attitudes with a Cronbach's alpha of .78 , thus indicating that it formed a highly reliable index of immigration opinion for the dependent variable.

\footnotetext{
${ }^{3}$ See online appendix 3 for all question wording
} 
In addition to attitudes toward national immigration policy, I also looked at attitudes towards the specific immigrants depicted in the story. There is a tendency, often referred to as person positivity bias, to evaluate individuals more favorably than policies considered in the abstract (LaPiere, 1934; Sears, 1983; Iyengar et al, 2013). To explore how the racialized physical traits of immigrants affected attitudes toward the individual immigrants depicted, respondents were asked whether the immigrants depicted in the story should be deported or allowed to stay in the United States. The question item, Immigrant Support, was coded on a four-point scale with higher scores indicating views that were more favorable to the depicted immigrants remaining in the U.S.

To allow some purchase on how proximity to the issue and relevant population may moderate the effects of racialized physical traits and assimilation on immigration attitudes, an additional question asked respondents how comfortable they would be "if a family like the one in the story moved into your neighborhood." The item, referred to as Social Distance, was recoded on a zero to one scale with higher scores indicating more positive feelings. The Social Distance question was expected to heighten personal proximity to the issue and its beneficiaries. By making the implications of the issue less abstract, this measure should more clearly reflect concerns about both unassimilated and non-white immigrants (Park, 1924).

To summarize, I expect that non-Latino white individuals will be less supportive of both liberal immigration policies, and an opportunity for individual immigrants to remain in the U.S., after reading a story about immigrants who are appear Unassimilated, relative to immigrants who appear Assimilated. I expect that the Race of immigrants, however, will not have a significant direct effect on either attitudes toward national immigration policies or the individual immigrants, when considered in an abstract or national context. When considering immigrants in 
one's own community, a measure of social distance, I hypothesize that not only Assimilation will be an important predictor of attitudes toward immigration, but that the immigrant's Race will as well. F expect that respondents will be less supportive of Dark Raced immigrants relative to Light Raced immigrants, and that a story priming people to think about Assimilated immigrants will produce more support for immigrants in one's own neighborhood than a story about

Unassimilated immigrants.

\section{Findings}

To assess the impact of the Race and Assimilation treatments, I began by running a 2 by 2 analysis of variance using the index of Immigration Policy Attitudes as the dependent variable. While attitudes seemed to be moving in a direction consistent with racial bias, the effect of Race on Immigration Policy Attitudes did not reach levels of statistical significance, $F(1,766)=0.71$, $p=.20^{4}$. So although the manipulation checks demonstrated that those in the Dark Raced conditions were more likely to be perceived as being from Africa, Southeast Asia or Latin America than those in the Light Raced conditions, there was no effect of Race on preferred federal immigration policies ${ }^{5}$. This finding is consistent with the reports of some previous studies indicating that the racialized physical traits of immigrants are not affecting attitudes towards national immigration policy (Hopkins, 2014; Iyengar et al., 2013).

Assimilation, on the other hand, affected immigration attitudes in a manner that was consistent with my hypothesis and previous work. As shown in Figure 1, Assimilation had a

\footnotetext{
${ }_{5}^{4}$ Because my hypotheses included a directional component, all results are reported as one-tailed tests.

${ }^{5}$ Due to evidence that people often seek to offer responses consistent with norms of racial equality despite implicit attitudes that counter these norms (Mendelberg 2001), I also consider the possibility that such social norms are leading respondents to mask their racial animus or discomfort as a matter of culture. Using a one-way analysis of variance, I find no support for the hypothesis that those exposed to the Dark Raced condition perceived the immigrants as being less Assimilated than those exposed to the Light Raced condition, $\mathrm{F}(1,759)=.26, \mathrm{p}=.30$. When looking at the effects of the treatment on treated, I also find no evidence that those who perceived the immigrants to be Dark Raced were perceived as less assimilated than those perceived to be Light Raced, $\mathrm{F}(1,759)=.30, \mathrm{p}=.29$.
} 
significant effect on Immigration Policy Attitudes with those in the Assimilated condition being more likely to have favorable attitudes toward immigration $(M=0.36, S E=0.01)$ than those in the Unassimilated condition, $(M=0.33 ; S E=0.01), F(1,766)=3.8, p=0.02$. This difference between the effect of Assimilation and that of Race was statistically significant $\mathrm{F}(1,758)=3.78$, $\mathrm{p}=.02$. Interestingly, there was no interaction effect between Race and Assimilation, so among both the more and less Assimilated immigrants, Race did not appear to affect attitudes towards immigration, $F(1,766)=0.34, p=.28$. In doing so, it adds to the surprising lack of support for a direct relationship between the racialized physical traits of a salient selection of immigrants and attitudes towards federal immigration policy.

\section{INSERT FIGURE 1 HERE}

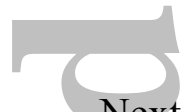

Next, I looked at whether Race and Assimilation had an effect on respondent views on what should happen to the specific immigrants depicted, as opposed to on broader immigration policy. Again, I used a 2 by 2 analysis of variance with Immigrant Support serving as the dependent variable. Consistent with my expectations and that of previous research, I find a similar pattern to what was found when looking at immigration policy attitudes (Harell et al., 2012; Iyengar et al., 2013). The Race of the immigrant did not appear to be related to evaluations of what should happen next to the specific immigrants depicted in the vignette $F(1,760)=0.00$, $\mathrm{p}=.47$, but Assimilation $\operatorname{did} \mathrm{F}(1,760)=3.40, \mathrm{p}=0.03$. Immigrants who were perceived to be more assimilated to mainstream American cultural norms were more likely to be seen as worthy of an opportunity to remain in the U.S $(M=0.69, S E=0.01)$. However, when viewing immigrants perceived to be less assimilated, respondents were more likely to favor deportation $(M=0.65$; $S E=0.01)$. It is important to note, however, that these differences were not statistically significant $\mathrm{F}(1,752)=1.53, \mathrm{p}=.11$. Thus, while Assimilation reached levels of statistical significance, the role 
of an immigrant's perceived level of assimilation was indistinguishable from the role of an immigrant's Race in shaping attitudes on how individual immigrants should be treated. Given that an immigrant's perceived level of Assimilation has repeatedly been shown to affect attitudes toward the individual immigrant in past studies (Sniderman et. Al., 2004; Newman et al, 2012; Wright \& Citrin 2011; Hainmueller \& Hopkins 2014), and that the limited sample size of this experiment detracts from the power of the analyses, the lack of significant difference between Race and Assimilations should introduce questions about the apparent non-role of Race.

\section{INSERT FIGURE 2 HERE}

To evaluate the impact of the treatments on one's preferred Social Distance from the immigrants portrayed, I ran an additional 2 by 2 analysis of variance with Social Distance serving as the dependent variable. Similar to the previous finding, those in the Assimilated condition were more likely to express accepting views of the immigrants portrayed $(M=0.69$, $S E=0.01)$ than those in the Unassmiliated condition $(M=0.62, S E=0.01), \mathrm{F}(1,761)=11.56$, $\mathrm{p}<0.00$. Yet unlike the findings for national Immigration Policy Attitudes, Immigrant Support and previous studies, Race did significantly affect preferred Social Distance, $\mathrm{F}(1,761)=3.82$, $\mathrm{p}=.02$ ). Those who viewed Dark Raced immigrants were less likely to want the immigrants portrayed living near them $(M=0.63, S E=0.01)$ than those who viewed Light Raced immigrants $(M=0.68, S E=0.01)$ (see Figure 3). So while Race did not have a direct effect on attitudes toward either national immigration policy, or the specific immigrants discussed when considered in an abstract context, Race had a clear effect on attitudes toward having the depicted immigrants in one's own community.

\section{INSERT FIGURE 3 HERE}




\section{EXPERIMENT TWO: VERIFYING THE ROLE OF RACE}

While a number of studies have confirmed the role of the culture traits or perceived assimilation of immigrants in attitudes toward immigration, this is among the first studies to point to a relationship between the radicalized physical traits of immigrants - independent of national origin - and attitudes toward immigration. I consequently sought to confirm the relationship between Race, Social Distance, and Immigration Policy Attitudes in a second experiment. This second survey experiment was administered to a sample of 902 adult white respondents through Amazon Mechanical Turk in July of 2015. I used a similar design to that of the first experiment by again exposing respondents to a vignette paired with a photograph. In contrast to the first experiment, however, the only manipulation in this experiment was the degree to which the immigrants were depicted with Afrocentric features - referred to in this paper as the immigrants' Race. To create this manipulation, I diverged from the method used for this manipulation in Experiment 1, and instead relied on image morphing. Image morphing provided a number of benefits. In particular, morphing (or blending) the images allowed me to manipulate the factor of interest (Afrocentric attributes) while minimizing the potential role of other attributes that can vary when relying on images of completely different heads - such as facial expressions, the direction which they were looking, the way their hair was styled, etc. The images used each depicted a scene with five individuals seated together in a living room-like setting (see online appendix 8). The setting, clothing, and other characteristics of the context depicted remained the same across conditions. The faces used in the experiment were drawn from a database of faces housed at the Center for the Neural Basis of Cognition at Carnegie Mellon University ${ }^{6}$. To create the final product, images of individuals identified in the

\footnotetext{
${ }^{6}$ Stimulus images courtesy of Michael J. Tarr, Center for the Neural Basis of Cognition and Department of Psychology, Carnegie Mellon University, http://www.tarrlab.org/. Funding provided by NSF award 0339122.
} 
database as African-American and Caucasian individuals were blended together in the ratio of 35:65 using Magic-Morph, a software application that allows digital blending of two images, and has been used for similar manipulations in the past (Bailenson et al., 2006; Li \& Tottenham, 2011). In the Dark Raced condition, the faces featured were a blend of the black ( 65 percent) and white (35 percent) individuals, while in the Light Raced condition, the faces featured were a blend of white (65 percent) and black (35 percent) individuals ${ }^{7}$.

I verified that respondents observed the racialized physical traits of the individuals depicted through the use of two manipulation checks. The first was the same as was used in Experiment 1, and asked respondents from which region they thought the immigrants depicted were most likely to have immigrated (see perceived country of origin by treatment in online appendix 9). Consistent with the manipulation, those in the Dark Raced condition were significantly more likely to say the immigrants depicted were from Africa, Latin America or Southeast Asia $(M=0.93, S E=0.01)$, than those in the Light Raced condition. Similarly, those in the Light Raced condition were significantly more likely to think the immigrants were from Europe $(M=0.83, S E=0.01), F(901)=26.21, \mathrm{p}=.00)$.

In a second manipulation check, I asked respondents to identify the skin color of the respondents that were depicted in the image at the beginning of the survey using the Massey and Martin Skin Color Scale (Massey et al. 2003). The scale was designed as an 11-point scale, ranging from zero to 10 , with zero representing albinism, or the total absence of color, and 10 representing the darkest possible skin. The scale used in the study depicts ten shades of skin color - corresponding to points 1 to 10 on the Scale - with each point represented by a hand, of

\footnotetext{
${ }^{7}$ Although respondents were randomly assigned to the Race treatment, balance checks (see online appendix 10) demonstrated that those who saw the Dark Raced treatment were more liberal than those who saw the Light Raced treatment. The confidence interval does account for imperfect randomizations, but variations in ideology between treatment groups were also accounted for by controlling for both ideological and partisan identity in the model (Mutz \& Pemantle, 2011).
} 
identical form, but different in color. Using this scale, those in the Dark Raced condition were more likely to indicate that the individuals featured had darker skin tones $(M=5.33 ; S E=.05)$ than those in the Light Raced condition $(M=3.83 ; S E=.05),(\mathrm{F}(1,896)=393.48, \mathrm{p}=.00)$.

The text of the vignette was similar to that used in Experiment 1. However, because the role of cultural assimilation was not being considered in this experiment, I removed language that would offer information on the cultural norms and practices of the immigrants depicted (see text in online appendix 7). The same three questions that were relied upon and combined into an index in Experiment 1, Immigration Policy Attitudes ${ }^{8}$, were again used to measure attitudes toward immigration in this second experiment. Similarly, the question used to measure social distance in Experiment 1 was also used in Experiment 2. However two additional measures of social distance were also included. The first of these tapped into one's level of comfort working with the immigrants depicted, and the second tapped into their level of comfort having those depicted marry into their family. The three questions were combined into an index, Social Distance Index, with a Cronbach's alpha of .91, indicating that it was highly reliable.

\section{Findings}

How did the Race of the depicted immigrants affect attitudes toward immigration policy and levels of comfort with the immigrants? As was found in Experiment 1, along with past research (Harell et al., 2012; Hopkins 2014; Iyengar et al., 2013), Race did not directly affect attitudes toward immigration policy $\mathrm{F}(1,896)=1.54, \mathrm{p}=.11)$. Yet similar to Experiment 1 , the effect of Race becomes much more pronounced on the Social Distance Index. Those who were exposed to Light Raced immigrants were more likely to feel comfortable around the immigrants depicted in

\footnotetext{
${ }^{8}$ As it did in Experiment 1, the index had a strong Cronbach's alpha (.89) in this experiment as well.
} 
socially proximate contexts $(M=0.75 ; S E=0.01)$ than those who were exposed to Dark Raced immigrants $(M=0.71 ; S E=0.01), \mathrm{F}(1,898)=6.25, \mathrm{p}=.00)^{9}$.

\section{INSERT FIGURE 4}

The findings presented thus far offer strong evidence that Race is, in fact, affecting attitudes toward immigrants. Yet while the lack of identification of the national origin of immigrants served to reduce the role of the immigrant's national origin in how respondents think about the immigrants depicted, it is valuable to look at the effects of Race within national origin groups as well. This is to say, if Race is in fact exerting an impact on immigration attitudes, this favoritism toward Light Raced immigrants should be evident when the immigrants are perceived to be of various national backgrounds, as well as when they are all perceived to be of a common origin.

To take up this question and reduce the variation in perceived origin of respondents, I looked at how the Race of immigrants affected responses just among those who perceived the respondents to be of Latin American origin. Latin America is both the most common region of origin of immigrants in recent years, and the region from which the largest number of respondents perceived the immigrants as having originated from (Zong \& Batalova, 2015). This made Latin American immigrants a highly relevant population to consider as well as the population with the largest sub-group sample, thereby permitting the most reliable sub-group analyses and inferences. In turn, I next looked at whether Race had an effect on Immigration Policy Attitudes and Social Distance among those who perceived the depicted immigrants to be of Latin American origin.

\section{INSERT FIGURE 5}

\footnotetext{
${ }^{9}$ These findings remain significant if I just look at the single measure of social distance used in the first experiment, as opposed to the index $(\mathrm{F}(1,897)=5.02, \mathrm{p}=.01)$.
} 
In line with previously reported results, the Race of the individuals perceived by respondents to be of Latin American origin did not demonstrate a direct effect on Immigration Policy Attitudes $\mathrm{F}(1,622)=2.48, \mathrm{p}=.07)$, but did affect attitudes toward Social Distance, $\mathrm{F}(1$, $622)=5.27, \mathrm{p}=.01$ ). Those exposed to Dark Raced immigrants were significantly less comfortable having the immigrants depicted in socially proximate contexts $(M=0.71 ; S E=0.01)$ than those in the Light Raced condition $(M=0.76 ; S E=0.01)$. On a 0 to 1 scale, with one indicating higher levels of comfort with the individuals depicted, comfort living near the Latino immigrants dropped over four percentage points from $75.9 \%$ to $71.1 \%$ when looking at Dark Raced immigrants relative to Light Raced immigrants.

To summarize my findings, Assimilation displayed a clear causal impact across three measures -immigration policy preferences, attitudes toward the individual immigrants, and the desired degree of social distance from the immigrants depicted. The racialized physical traits of the immigrants under consideration, on the other hand, had a more nuanced relationship with immigration attitudes. As had been demonstrated in past research, Race did not display the same significant direct effects on Immigration Policy Attitudes or toward the individual immigrants as did Assimilation. Yet there was still clear evidence of a relationship between the Race of immigrants and the attitudes people had toward them. White respondents indicated greater opposition to immigrants in close social contexts when they had more Afrocentric features. Additionally, this desire for greater Social Distance from Dark Raced immigrants was related to less support for immigration on a national level, thereby indirectly linking racialized physical traits and attitudes toward federal immigration policy. 


\section{DISCUSSION}

Throughout U.S. history, there have been people who have been welcomed into the US, and there have been people who have been regarded as unworthy. Self-appointed, volunteer border enforcement, as well as the millions of people who joined protests in pursuit of immigration reform, each highlight the strength of public sentiment on immigration. Yet public opinion assessments indicate a great deal of ambivalence, making it difficult to characterize US opinion on this issue.

Consistent with my hypothesis and past work, priming people to think about immigrants with greater levels of assimilation to mainstream U.S. cultural norms increased: support for more liberal immigration policies, support for the individual immigrants having an opportunity to stay in the U.S., and the respondent's level of comfort being in socially proximate contexts with the depicted immigrants. These findings reinforce previous research suggesting that Americans favor immigrants giving up their "foreign ways" of life and immersing themselves into mainstream American cultural norms (Lapinski et al., 1997; Newman et al., 2012). Further, they demonstrate that cultural ethnocentrism continues to pervade attitudes toward immigrants and immigration. Even the simplest sources of difference - language, food, and an interest in issues occurring outside the U.S. - are enough to make many Americans uncomfortable with national newcomers. As opposed to seeing cultural difference as an opportunity for positive change, many Americans seem to see it as a source of concern.

Yet particularly notable was the relationship demonstrated between the racialized physical traits of salient immigrants and attitudes towards immigration. Individual responses to questions that tap socially sensitive issues, such as race, can be difficult to measure. In this paper, a social distance measure offered further insights into how race and racialized traits are affecting 
immigration attitudes. Making non-white immigrants salient directly increased opposition to immigrants in a respondent's own community. This effect was found independent of the regional origin of the salient immigrants. Among respondents who held the same view on the regional origin of the depicted immigrants, as well as among those respondents who held different views on the regional origin of the salient immigrants, the immigrants Race was found to play an important role in immigration attitudes.

The absence of a statistically significant direct relationship between Race and attitudes toward national immigration policy should be interpreted with caution. In none of these tests was Race particularly far from reaching traditional levels of statistical significance. And particularly notable, across two separate experiments and three different measures, the direction of the relationship between Race and attitudes toward immigration was in line with evidence that people are generally less supportive of those with Afrocentric physical features. So while these effects were not "significant," according to the standard practice of interpreting the term, they were certainly consistent.

Together, these findings counter past research suggesting that there is not a relationship between the racialized physical traits of a salient immigrant and punitive attitudes towards immigrants (Harell et al., 2012; Hopkins, 2014; Iyengar et al., 2013; Sniderman et al., 1991). In particular, they highlight the nuanced and important ways that the racialized physical traits of salient figures are affecting public opinion and attitudes toward policy issues.

With these results in mind, it is valuable to note the limitations of the study. First, the vignette used was not a news story (nor was it presented as such), and the image used was not a professional news image. To the extent that a lack of realism may have affected respondent views, however, they would likely reduce the likelihood of the manipulations affecting 
individual attitudes and make it a more stringent test of their relevance. Furthermore, despite these limitations, manipulations checks clearly verified that respondents perceived both the Race and the Assimilation manipulations.

It is also worthwhile to note that while Assimilation and Race did have a significant effect on attitudes, the size of the estimated effects were not especially large. So although perceptions of an immigrants level of assimilation and racialized physical attributes shifted public opinion on issues relating to immigration, it did not do so in a manner that drastically changed views. Of course, this potential limitation should be qualified by the fact that real news stories, with professional images, and a real context would likely have a much more powerful effect than the artificial one used in this experiment. In turn, there is good reason to believe that the small effect observed in this experiment would be much larger in real life.

At the heart of these findings, one finds continued support for the idea that the way people form views on distant policy matters can diverge substantially from how individuals form views on issues closer to home. This study offers additional evidence that racialized physical traits, unfortunately, continue to be among these matters. Far from being removed from attitudes toward immigration, the racialized physical attributes of salient immigrants are deeply implicated in how people think about immigration. Thus, even though the questions may be about general policies or populations, people's answers will vary based on the kinds of immigrants they have in mind, and where those immigrants are. Because what is at the top of one's mind inevitably changes over time, this provides one more explanation for the many inconsistencies that are observed in assessments of immigration policy opinion. 


\section{WORKS CITED}

Allen, T. (1994/1997). The Invention of the White Race. London: Verso.

Bailenson, J., Garland, P., Iyengar, S., \& Yee, N. (2006). Transformed facial similarity as a political cue: A preliminary investigation. Political Psychology, 27(3), 373-385.

Blair, I., Judd, C., Sadler, M., \& Jenkins, C. (2002). The role of afrocentric features in person perception: Judging by features and categories. Journal of Personality and Social Psychology, $83(1), 5-25$.

Bobo, L. (2011). Somewhere between Jim Crow \& Post-Racialism: Reflections on the racial divide in America today. Daedalus, 140 (2), 11-36.

Bobo, L., Charles, C., Krysan, M. \& Simmons, A. (2012). The real record on racial attitudes. In P. V. Marsden (Ed.), Social trends in American public life: Findings from the General Social Survey (38-83). Princeton: Princeton University Press.

Brader, T., Valentino, N., \& Suhay, E. (2008). What triggers public opposition to immigration? Anxiety, group cues, and immigration threat. American Journal of Political Science, 52(4), 959978.

Branton R., Cassese, E., Jones, B., \& Westerland, C. (2011). All along the watchtower: acculturation fear, anti-Latino affect, and immigration. Journal of Politics. 73, 664-79.

Buchanan, P. (2006). Nation or notion? American Conservative, 5 (18), 12-16.

Burns, P. \& Gimpel, J. (2000). Economic insecurity, prejudicial stereotypes, and public opinion on immigration policy. Political Science Quarterly, 115(2), 201-225.

Chandler, C. \& Tsai, Y. (2001). Social factors influencing immigration attitudes: An analysis of data from the general social survey. Social Science Journal, 38, 177-188.

Chang, L. \& Krosnick, J. (2009). National surveys via RDD telephone interviewing vs. the Internet: Comparing sample representativeness and response quality. Public Opinion Quarterly, 73, 641-678.

Charles, C. (2000). Neighborhood racial-composition preferences: Evidence from a multiethnic metropolis. Social Forces, 47 (3), 379-407.

Citrin, J. (1990). Language politics and American identity. Public Interest, 99, 96-109.

Citrin, J. \& Green, D. (1997). Public opinion toward immigration reform: The role of economic motivations. Journal of Politics, 59(3), 858-881. 
Citrin, J, Green, D., Muste, C., \& Wong, C. (1997). Public opinion toward immigration reform: The role of economic motivations. Journal of Politics, 59, 858-81.

Cowan, S. (2003). NIMBY syndrome and public consultation policy: The implications of a discourse analysis of local responses to the establishment of a community mental health facility. Health \& Social Care in the Community. 11 (5), 379-386.

Davis, B. \& Bali, V. (2008). Examining the role of race, NIMBY, and local politics in FEMA trailer park placement. Social Science Quarterly, 89 (5), 1175-1194.

Dixon T. \& Maddox, K. (2005). Skin Tone, Crime News, and Social Reality Judgments: Priming the Stereotype of the Dark and Dangerous Black Criminal. Journal of Applied Social Psychology, 35:1555-70.

Durrheim, K. \& Dixon, J. (2004). Attitudes in the fiber of everyday life: The discourse of racial evaluation and the lived experience of desegregation. American Psychologist, 59(7), 626-636.

Djamba, Y.\& Kimuna, S. (2014). Are Americans really in favor of interracial marriage? A closer look at when they are asked about black-white marriage for their relatives. Journal of Black Studies, 45 (6), 528-544.

Eberhardt, J., Goff, P., Purdie, V., \& Davies, P. (2004). Seeing Black: Race, Crime, and Visual Processing. Journal of Personality and Social Psychology, 6:876-93.

Frey, W. (2006). Immigrants are everywhere. The Milken Institute Review, 2, 6-7.

Gilens, M. (1995). Racial attitudes and opposition to welfare. The Journal of Politics, 57 (4), 994-1014.

Giles, M. \& Hertz, K. (1994). Racial threat and partisan identification. American Political Science Review, 88, 317-326.

Glaser, J. (1994). Back to the Black Belt: Racial Environment and White Racial Attitudes in the South. Journal of Politics, 56, 21-41.

Golby, A., Gabrieli, J., Chiao, J., \& Eberhardt, J. (2001). Differential Responses in the Fusiform Region to Same-Race and Other-Race Faces. Nature Neuroscience, 4(8):845-50.

Gordon, M. (1978). Human nature, class, and ethnicity. New York: Oxford University Press. Greenberg, C. (2012). Liberal NIMBY: American Jews and civil rights. Journal of Urban History, 38(3), 452-466.

Grovum, J. (2014, Aug. 8). The English-only debate heats up again. Governing. Retrieved from http://www.governing.com/news/headlines/the-english-only-debate-heats-up-again.html. 
Hainmueller, J. \& Hopkins, D. (2014). The Hidden American Immigration Consensus: A Congoing Analysis of Attitudes toward Immigrants. American Journal of Political Science, 59(3): 529-548.

Haney-López, I. (2006). White by Law: The Legal Construction of Race. New York: New York University Press.

Harell, A., Soroka, S., Iyengar, S., \& Valentino, N. (2012). The impact of economic and cultural cues on support for immigration in Canada and the United States. Canadian Journal of Political Science, 45(3), 499-530.

Harris, A. (2008). From color line to color chart?: Racism and colorism in the new century. Berkeley Journal of African-American Law and Policy, 10(1), 52-69.

Hopkins D. (2011). National debates, local responses: The origins of local concern about immigration in Britain and the United States. British Journal of Political Science. 41, 499-524.

Hopkins, D. (2014). The upside of accents: Language, skin tone, and attitudes toward immigration. British Journal of Political Science, 10, 1-27.

Huckfeldt, R. \& Kohfeld, C. (1989). Race and the decline of class in American politics. Urbana: University of Illinois Press.

Huntington, S. (2004, March/ April). The Hispanic Challenge. Foreign Policy, 30-45.

Hutchings, V. \& Valentino, N. (2004). The centrality of race in American politics. Annual Review of Political Science, 7, 383-408.

Iglesias, T. (2002). Managing local opposition to affordable housing: a new approach to NIMBY. Journal of Affordable Housing and Community Development Law, 12(1), 78-122.

Iyengar, S., Jackman, S., Messing, S., Valentino, N., Aalberg, T., Duch, R., Hahn, K., Soroka, S., Harell, A, \& Kobayashi, T. (2013). Do attitudes about immigration predict willingness to admit individual immigrants? A cross-national test of the person-positivity bias. Public Opinion Quarterly, 77 (3), 641-665.

Janus, A. (2010). The Influence of Social Desirability Pressures on expressed Immigration Attitudes. Social Science Quarterly, 91(4), 928-946.

Kinder D. \& Sanders, L. (1996). Divided by Color: Racial Politics and Democratic Ideals. Chicago: University of Chicago Press.

Kinder, D. \& Mendelberg, T. (1995). Cracks in American apartheid: the political impact of prejudice among desegregated whites. Journal of Politics, 57(2), 402-424. 
Kuklinski, J., Cobb, J. \& Gilens, M. (1997). Racial attitudes and the "new south.” Journal of Politics, 59 (2), 323-349.

LaPiere, R. T. (1934). Attitudes vs. actions. Social Forces, 13(2),230-237.

Lapinski, J., Peltola, P., Shaw, G., \& Yang, A. (1997). Trends: Immigrants and immigration. Public Opinion Quarterly, 61, 356-383.

Li, Y. \& Tottenham, N. (2011). Seeing yourself helps you see others. Emotion, 11(5), 12351241.

Maddox, K. B. \& Gray, S. A. (2002). Cognitive Representations of Black Americans: ReExploring the Role of Skin Tone. Personality and Social Psychology Bulletin, 28(2),250-59.

Massey, D., Charles, C., Lundy, G., \& Fischer, M. (2003). The Source of the River: The Social Origins of Freshmen at America's Selective Colleges and Universities. Princeton, NJ: Princeton University Press.

Mendelberg, T. (2001). The Race Card: Campaign Strategy, Implicit Messages, and the Norm of Equality. Princeton, NJ: Princeton University Press.

Milkman, K., Akinola, M, \& Chugh, D. (2012). Temporal distance and discrimination: An audit study in academia. Psychological Science, 23 (7), 710-717.

Mutz, D. \& Pemantle, R. (2011). The perils of randomization checks. Unpublished Manuscript. Retrieved at https://www.math.upenn.edu/ pemantle/papers/Preprints/perils.pdf.

Myrdal, G. (1944). An American Dilemma: The Negro Problem and Modern Democracy. New York: Random House.

Newman, B., Hartman, T., \& Taber, C.S. (2012). Foreign language exposure, cultural threat, and opposition to immigration. Political Psychology, 33(5), 635-657.

Oliver, J. \& Mendelberg, T. (2000). Reconsidering the environmental determinants of White racial attitudes. American Journal of Political Science, 44(3), 574-589.

Pager, D., Western, B. \& Bonikowski, B. (2009). Discrimination in a low-wage labor market: A field experiment. American Sociological Review, 74(5), 777-799.

Park, R. (1924). The concept of social distance as applied to the study of racial attitudes and racial relations. Journal of Applied Sociology, 8, 339-344.

Paxton, P. \& Mughan, A. (2006). What's to fear from immigrants? Creating an assimilationist threat scale. Political Psychology. 24 (4), 549-568. 
Pérez, E. (2010). Explicit evidence on the import of implicit attitudes: the IAT and immigration policy judgements. Political Behavior, 32(4): 517-545.

Pew Research Center. (2006). America's immigration quandary: No consensus on immigration problem or proposed fixes. Retrieved at: http://www.people-press.org/files/legacy-pdf/274.pdf.

Portes, A., Parker, R., \& Cobas, J. A. (1980). Assimilation or consciousness: Perceptions of U.S. society among recent Latin American immigrants to the United States. Social Forces, 59(1), 200-224.

Sanchez, G. (1997). Immigrant Adaptation and Native-Born Responses in the Making of Americans, International Migration Review, 31 (4), 1009-1030.

Schildkraut, D. (2005). Press One for English: Language Policy, Public Opinion, and American Identity. Princeton, NJ: Princeton University Press.

Schildkraut, D. (2011). Americanism in the Twenty-First Century: Public Opinion in the Age of Immigration. New York, NY: Cambridge University Press.

Schuman, H., Steeh, C., Bobo, L. \& Krysan, M. (1997). Racial Attitudes in America: Trends and Interpretations. Cambridge: Harvard University Press.

Sears, D. (1983). The person-positivity bias. Journal of Personality and Social Psychology, 44(2), 233-250.

Sears, D., Van Laar, C., Carrillo, M., \& Kosterman, R. (1997). Is it really racism? The origins of white Americans' opposition to race-targeted policies. Public Opinion Quarterly, 61 (1), 16-53.

Short, R. \& Magaña, L. (2002). Political rhetoric, immigration attitudes, and contemporary prejudice: A mexican american dilemma. The Journal of Social Psychology, 142(6), 701-712.

Sniderman, P., Piazza, T., Tetlock, P. \& Kendrick, A. (1991). The new racism. American Journal of Political Science, 35(2), 423-447.

Sniderman, P., Hagendoorn, L., \& Prior, M. (2004). Predisposing factors and situational triggers: Exclusionary reactions to immigrant minorities. American Political Science Review, 98(1), 3549.

Taylor, M. (1998). Local racial/ ethnic proportions and white attitudes: numbers count. American Sociological Review, 63, 56-78.

Valentino, N., Hutchings, V., \& White, I. (2002). Cues that matter: How political ads prime racial attitudes during campaigns. The American Political Science Review, 96 (1), 75-90.

Weaver, V. (2012). The electoral consequences of skin color: The "hidden" race side of race in politics. Political Behavior, 34(1):159-192. 
Wilson, J. \& Svajlenka, N. (2014). Immigrants Continue to Disperse, with Fastest Growth in the Suburbs. Retrieved from http://www.brookings.edu/research/papers/2014/10/29-immigrantsdisperse-suburbs-wilson-svajlenka.

Wright, G. (1977). Contextual models of electoral behavior: The southern Wallace vote. American Political Science Review, 71, 497-508.

Wright, M. \& Citrin, J. (2011). Saved by the stars and stripes? Images of protest, salience of threat, and immigration attitudes. American Politics Research, 39(2), 323-43.

Wright, M., Levy, M. \& Citrin, J. (2015). Public attitudes toward immigration policy across the legal/illegal divide: The role of categorical and attribute based decision making. Political Behavior, 1-25.

Zaller, J. \& Feldman, S. (1992). A simple theory of the survey response: Answering questions versus revealing preferences. American Journal of Political Science, 36(3), 579-616.

Zong, J. \& Batalova, J. (2015). Frequently requested statistics on immigrants and immigration in the United States. Retrieved from http://www.migrationpolicy.org/article/frequently-requestedstatistics-immigrants-and-immigration-united-states. 
FIGURE 1. Effect of Assimilation and Racialized Physical Traits on Attitudes Toward Immigration

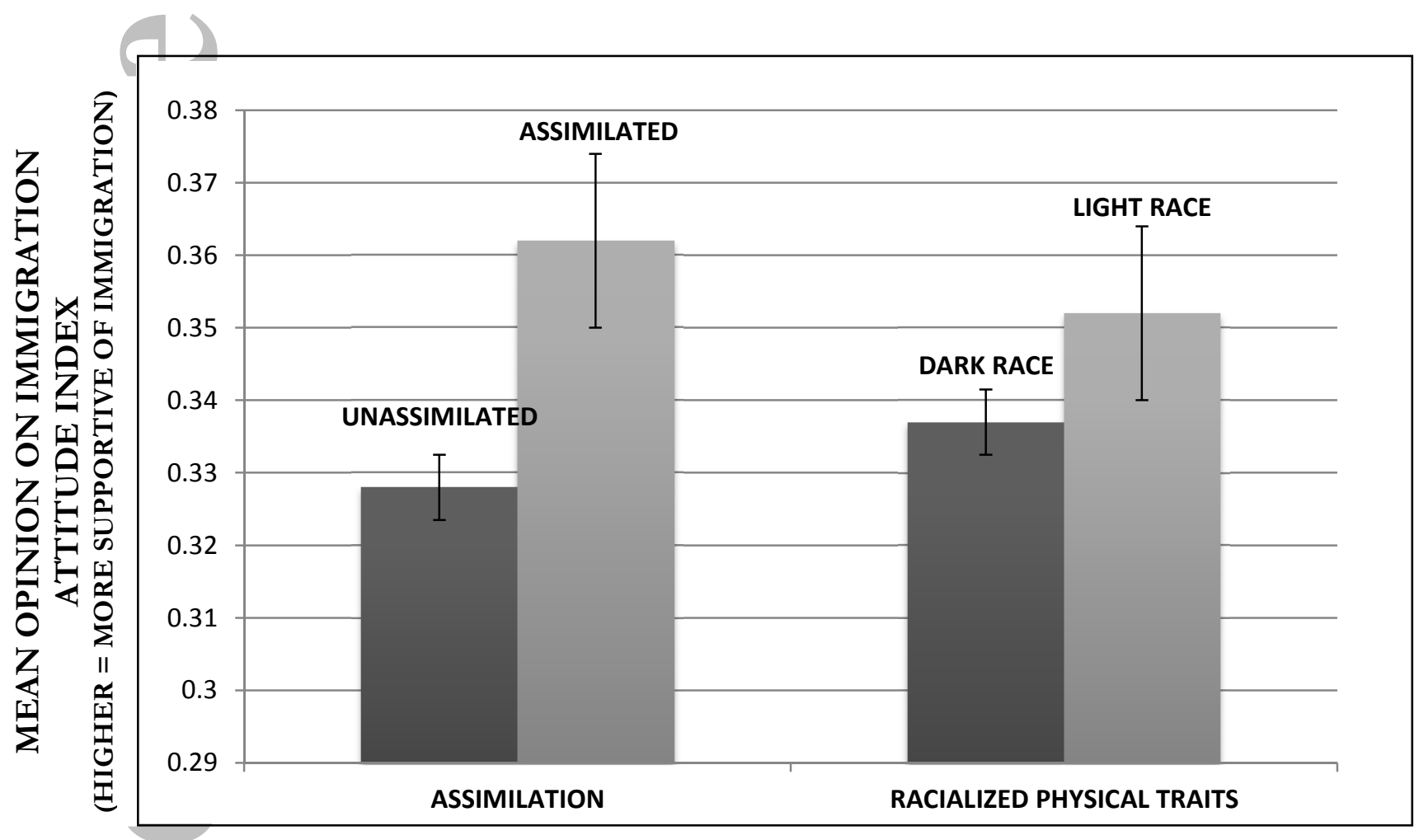

Note: Entries are means by experimental condition. All scales ranged from zero to one, with one indicating less restrictive attitudes toward immigration. Assimilation had a significant effect on attitudes $F(1,766)=3.81, p=0.02$, whereas Race did not, $F(1,766)=0.71, \mathrm{p}>0.05$. The difference in the effects of Race and Assimilation was also statistically significant, $\mathrm{p}=0.02$. 
FIGURE 2. Effect of Assimilation and Racialized Physical Traits on Support for Allowing Immigrants to Remain in the United States

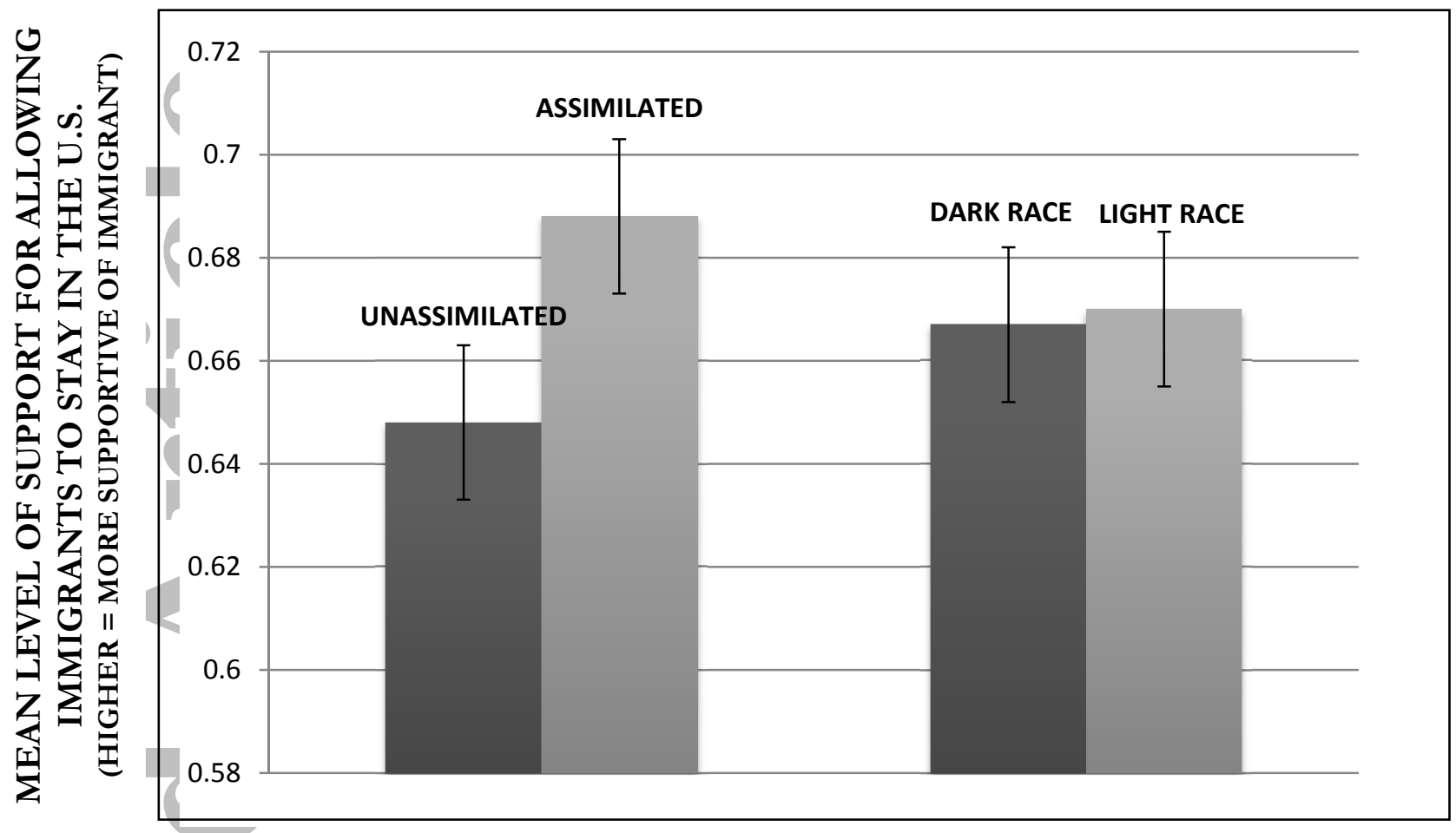

Note: Entries are means by experimental condition. The scale ranges from zero to one, with one indicating greater support for allowing the immigrants depicted to remain in the U.S. and zero indicating greater support for deporting the immigrants depicted. Assimilation had a significant effect on support for allowing immigrants to remain in the United States $\mathrm{F}(1,760)=3.40, \mathrm{p}=0.03$, whereas Race did not $\mathrm{F}(1,760)=0.0, \mathrm{p}>0.05$. The difference between the effects of Race and Assimilation was not statistically significant $(\mathrm{p}>0.05)$. 
FIGURE 3. Effect of Assimilation and Racialized Physical Traits on Social Distance

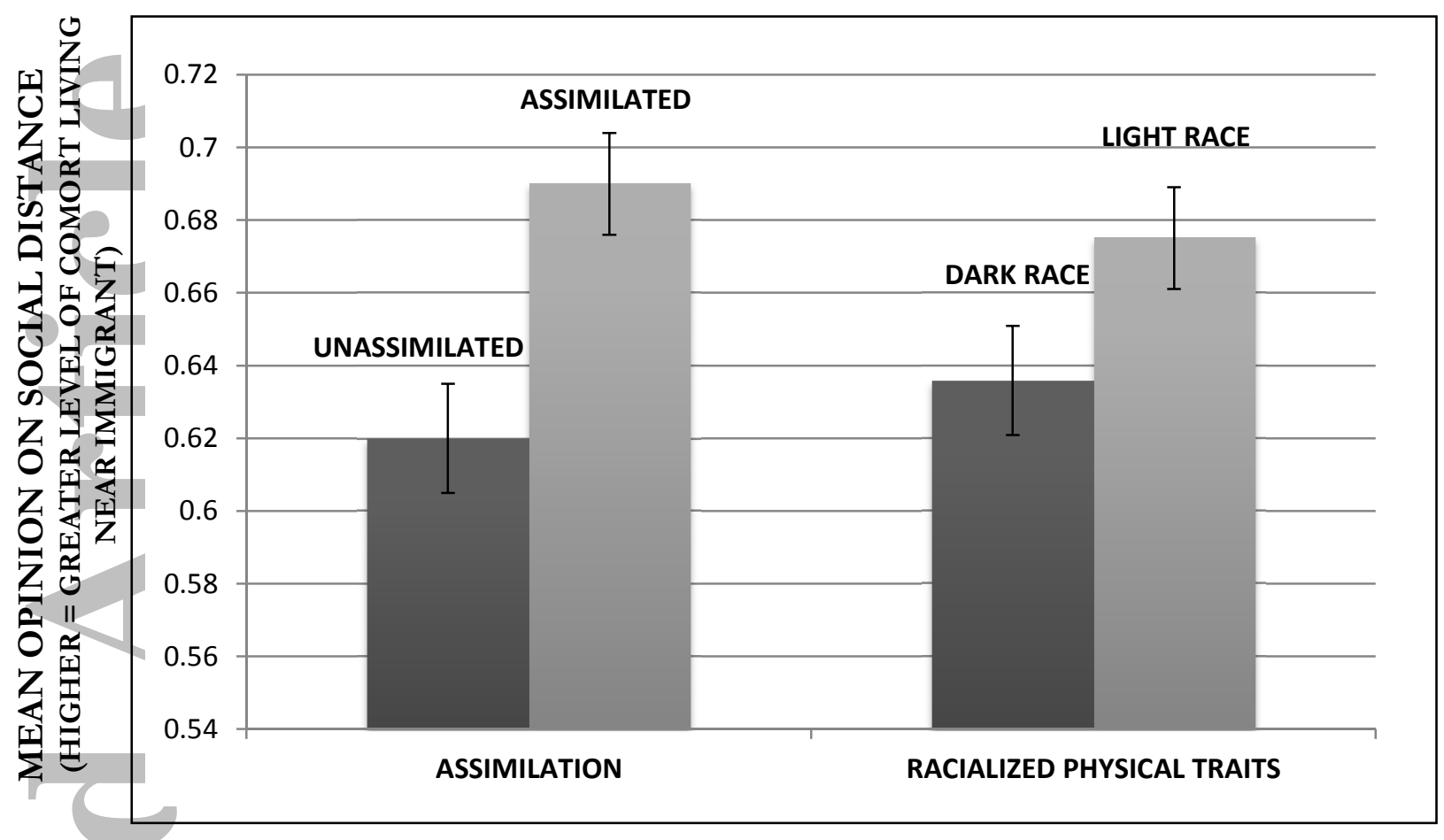

Note: Entries are means by experimental condition. The scale ranges from zero to one, with one indicating higher levels of comfort having the depicted immigrants live in the respondent's neighborhood. Assimilation, F(1, 761)=11.56, $\mathrm{p}<0.00$, and Race $\mathrm{F}(1$, $761)=3.82, \mathrm{p}=.02$ ) had significant effects on social distance. 
FIGURE 4. Effect of Racialized Physical Traits on Difference in Social Distance and Immigration Attitudes

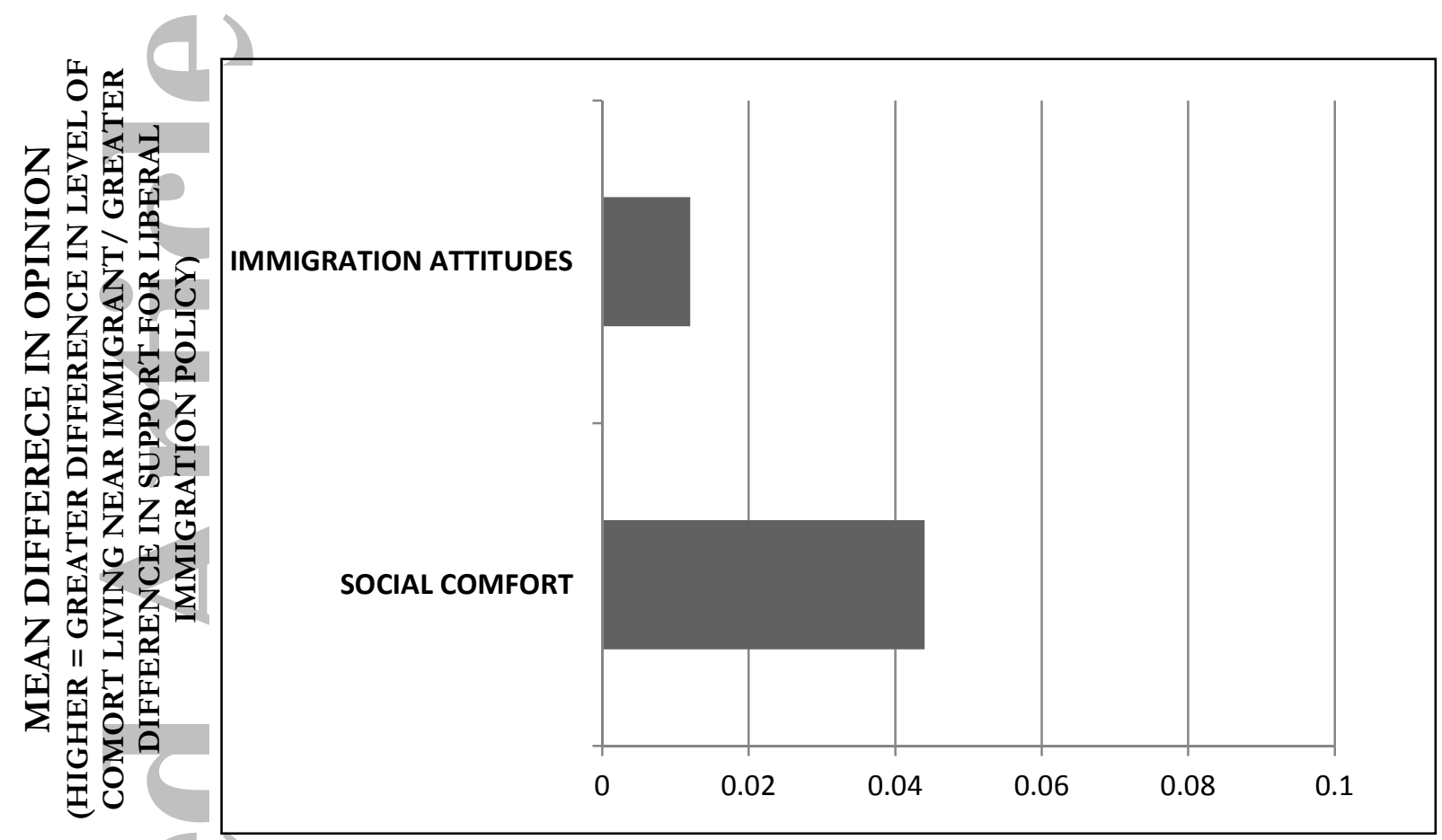

Note: Entries are mean differences in levels of support for Light Raced immigrants over Dark Raced immigrants on Immigration Policy Attitudes and Social Distance. The scales range from zero to one, with one indicating higher levels of comfort with the immigrants depicted, and less restrictive attitudes towards assimilation. Race $\mathrm{F}(1,898)=6.25, \mathrm{p}=.00$ ) had significant effects on social distance, but not attitudes toward immigration $\mathrm{F}(1,896)=1.54$, $\mathrm{p}>.05$ ). 
FIGURE 5. Effect of Racialized Physical Traits on Difference in Social Distance and Immigration Attitudes, Among Respondents who Perceived Immigrants to be Latino

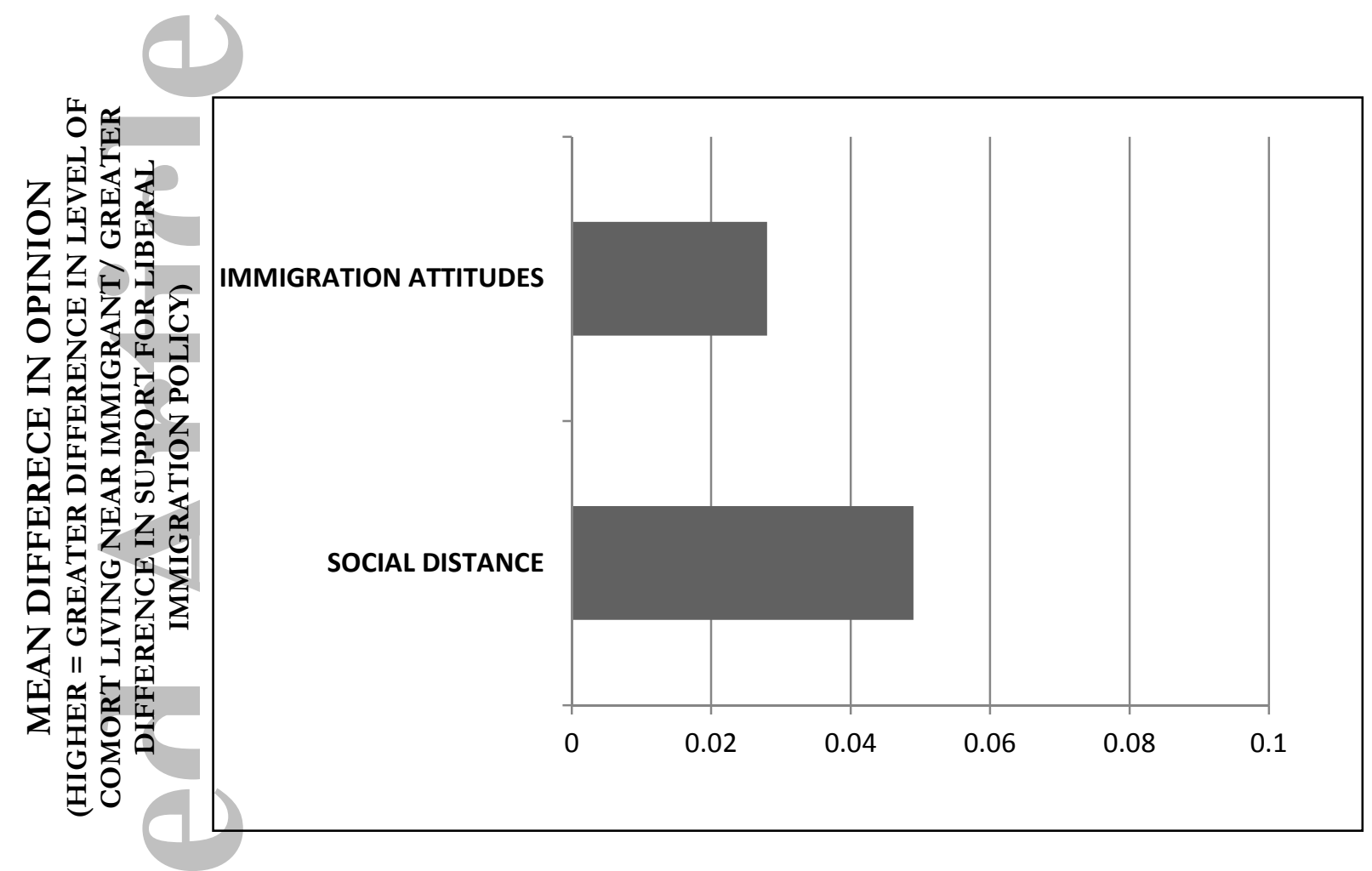

Note: Entries are mean differences in levels of support for Light Raced immigrants over Dark Raced immigrants on Immigration Policy Attitudes and Social Distance, among respondents who perceived the immigrants depicted to be of Latin American origin. The scales range from zero to one, with one indicating higher levels of comfort with the immigrants depicted, and less restrictive attitudes towards assimilation. Race $\mathrm{F}(1$, $622)=5.27, p=.01$ ) had significant effects on social distance, but not attitudes toward immigration $\mathrm{F}(1,622)=2.48, \mathrm{p}>.05)$. 


\section{ONLINE APPENDIX 1: PHOTOS, EXPERMIENT 1}

Dark Raced Condition*

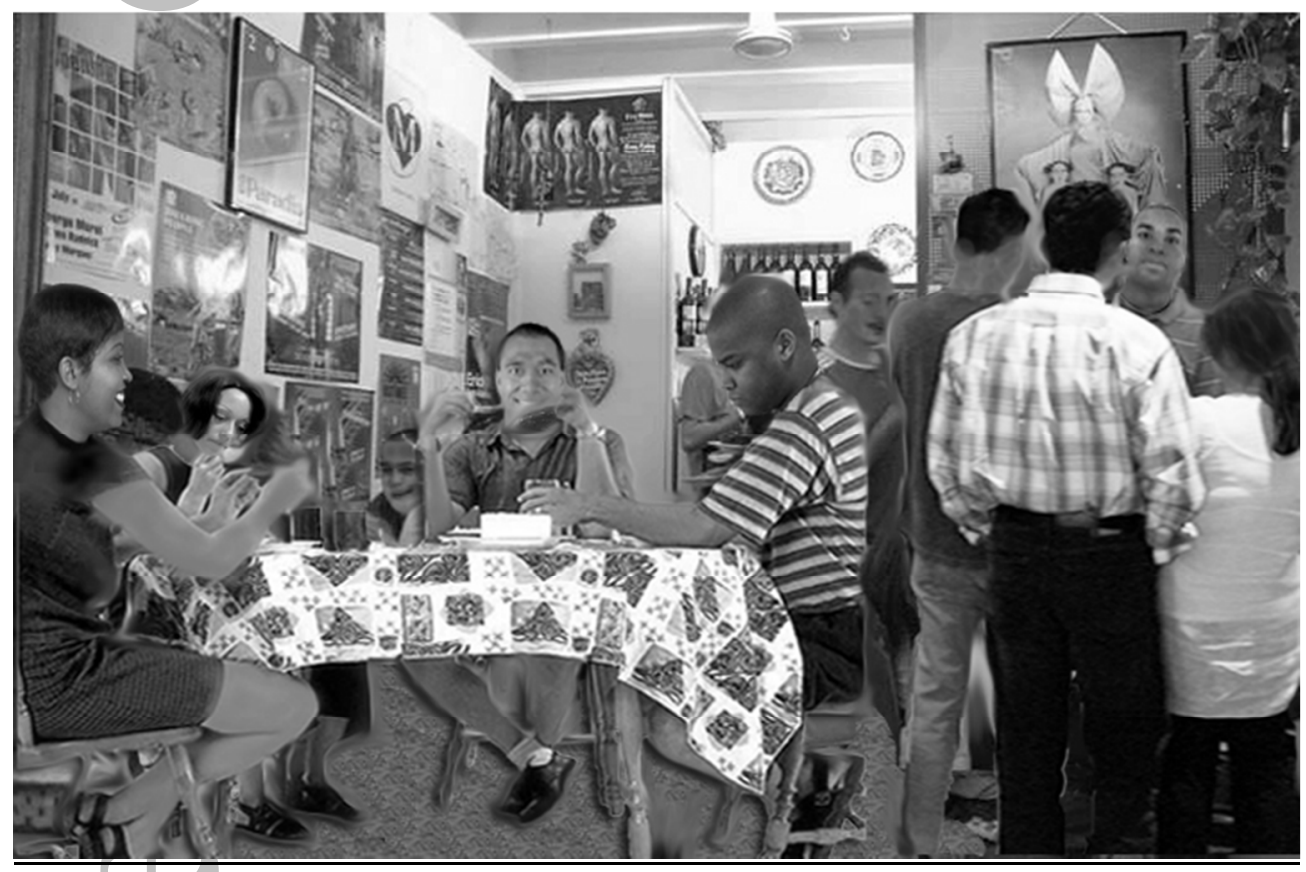

Light Raced Condition*

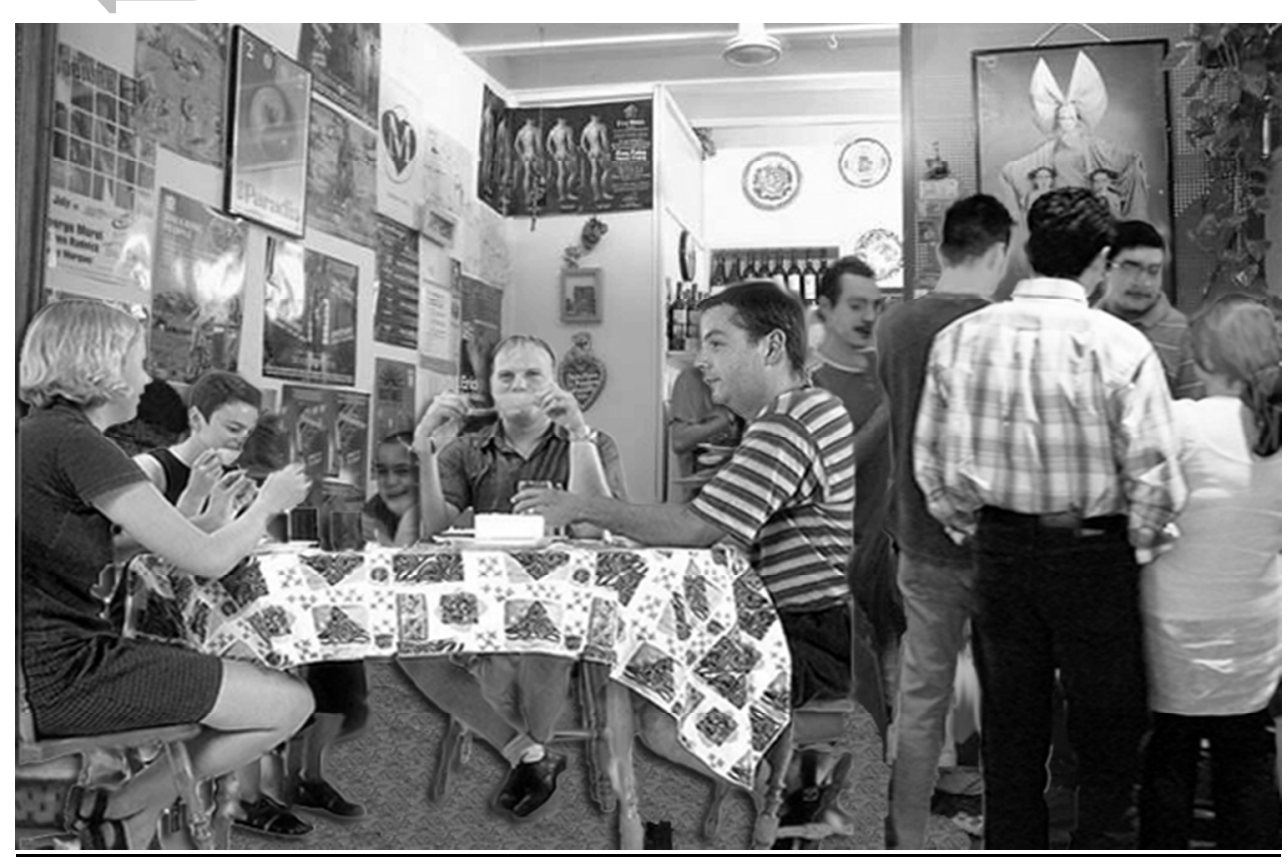

*Note: Original photos used in experiment were in full color. 


\section{ONLINE APPENDIX 2: VIGNETTE, EXPERIMENT 1}

In Montgomery, Illinois, an immigrant family gets together for lunch at [Assimilated: Roy's Diner/Not Assimilated: an ethnic food market]. As they are served [Assimilated: a platter of mozzarella sticks, onion rings and buffalo wings / Not Assimilated: trays of spicy goat meat], the Lina family chats [Not Assimilated: in their native tongue] about [Assimilated: the local baseball team's previous season/ Not Assimilated: the new school they sent money to build back in their home country].

Yet beneath the apparent cheer of the Lina family's conversation is anxiety surrounding the aggressive lobbying by local advocates for stricter immigration laws.

The most severe proposal would deport all immigrants who did not initially enter the country legally - regardless of reason - to return to their native countries and reapply for admission. For the Lina family, this would mean returning to the persecution of a military dictatorship.
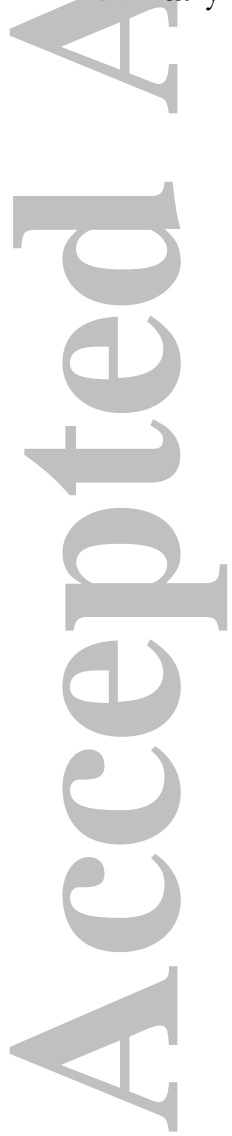


\section{ONLINE APPENDIX 3 : Question Text}

\section{Race Manipulation Check:}

"What country do you think the immigrants in the story came from? Please give us your best guess. 1) A country in Africa; 2) A country in Eastern Europe; 3) A country in Latin America; 4) A country in Western Europe; 5) A country in Southeast Asia; 6) Australia."

\section{Assimilation Manipulation Check:}

"During their time in the United States, do you think these immigrants have... 1) Adopted mostly American ways of life; 2) Adopted some American ways of life; 3) Mostly kept to the ways of life from their home country; 4) Completely kept to the ways of life from their home country." Coded on a zero to one scale so that high scores indicate greater perceived assimilation.

\section{Immigration Policy Attitudes Index:}

1) "Overall, do you think immigrants are helping or hurting America?"

2) "Do you think the number of immigrants in this country should be increased, decreased, or kept about the same?" 3) "Please indicate whether you favor or oppose the following proposal addressing immigration: Increase border security by building a fence along part of the US border with Mexico." All items were coded on a zero to one scale so that high scores indicate less restrictive attitudes toward immigration. All items were combined into an index of policy attitudes by taking the mean across the three items.

\section{Immigrant Support:}

"Thinking about the Lina family that was discussed in the article, what do you think should happen to them? Should they be deported/allowed to stay?" Coded on a zero to one scale so that high scores indicate greater support for allowing immigrants to stay in the US.

\section{Social Distance}

"How comfortable would you be if a family like the one in the story moved into your neighborhood." Coded on a zero to one scale so that high scores indicate greater comfort with the individuals depicted.

\section{Social Distance Index}

1) "How comfortable would you be if a family like the one in the story moved into your neighborhood." Coded on a zero to one scale so that high scores indicate greater comfort with the individuals depicted.

2) "How comfortable would you be working with individuals like those in the story?" Coded on a zero to one scale so that high scores indicate greater comfort with the individuals depicted. 3) "How comfortable would you be if someone from your family married someone like the individuals in the story?" Coded on a zero to one scale so that high scores indicate greater comfort with the individuals depicted. 
ONLINE APPENDIX 4: PERCEIVED COUNTRY OF ORIGIN BY TREATMENT, EXPERIMENT 1

\begin{tabular}{lcccc}
\hline & Light Skin & Dark Skin & Assimilated & $\begin{array}{l}\text { Not } \\
\text { Assimilated }\end{array}$ \\
\hline Africa & $4.6 \%$ & $14.1 \%$ & $11.3 \%$ & $7.4 \%$ \\
$\begin{array}{l}\text { Eastern Europe } \\
\text { Latin America }\end{array}$ & $28.5 \%$ & $8.6 \%$ & $22.3 \%$ & $14.9 \%$ \\
$\begin{array}{l}\text { Western } \\
\text { Europe }\end{array}$ & $48.8 \%$ & $62.8 \%$ & $47.1 \%$ & $64.4 \%$ \\
Southeast Asia & $7.2 \%$ & $3.5 \%$ & $6.2 \%$ & $6.5 \%$ \\
Australia & $1.1 \%$ & $10.8 \%$ & $12.7 \%$ & $5.8 \%$ \\
\hline TOTAL & $\mathbf{1 0 0} \%$ & $0.3 \%$ & $0.4 \%$ & $0.9 \%$ \\
\hline
\end{tabular}


ONLINE APPENDIX 5: PERCEIVED ASSIMILATION BY TREATMENT, EXPERIMENT 1

\begin{tabular}{|c|c|c|c|c|}
\hline & Light Skin & Dark Skin & Assimilated & $\begin{array}{l}\text { Not } \\
\text { Assimilated }\end{array}$ \\
\hline $\begin{array}{l}\text { Adopted mostly } \\
\text { American ways of life }\end{array}$ & $10.2 \%$ & $9.2 \%$ & $16.2 \%$ & $3.2 \%$ \\
\hline $\begin{array}{r}\text { Adopted some } \\
\text { American ways of life }\end{array}$ & $56.6 \%$ & $56.0 \%$ & $63.4 \%$ & $49.1 \%$ \\
\hline $\begin{array}{l}\text { Mostly kept to the } \\
\text { ways of life from their } \\
\text { home country }\end{array}$ & $29.6 \%$ & $31.3 \%$ & $18.5 \%$ & $42.4 \%$ \\
\hline $\begin{array}{l}\text { Completely kept to } \\
\text { the ways of life of } \\
\text { their home country }\end{array}$ & $3.6 \%$ & $3.5 \%$ & $1.8 \%$ & $5.3 \%$ \\
\hline TOTAL & $100 \%$ & $100 \%$ & $100 \%$ & $100 \%$ \\
\hline
\end{tabular}




\section{ONLINE APPENDIX 6: BALANCE CHECKS, EXPERIMENT 1}

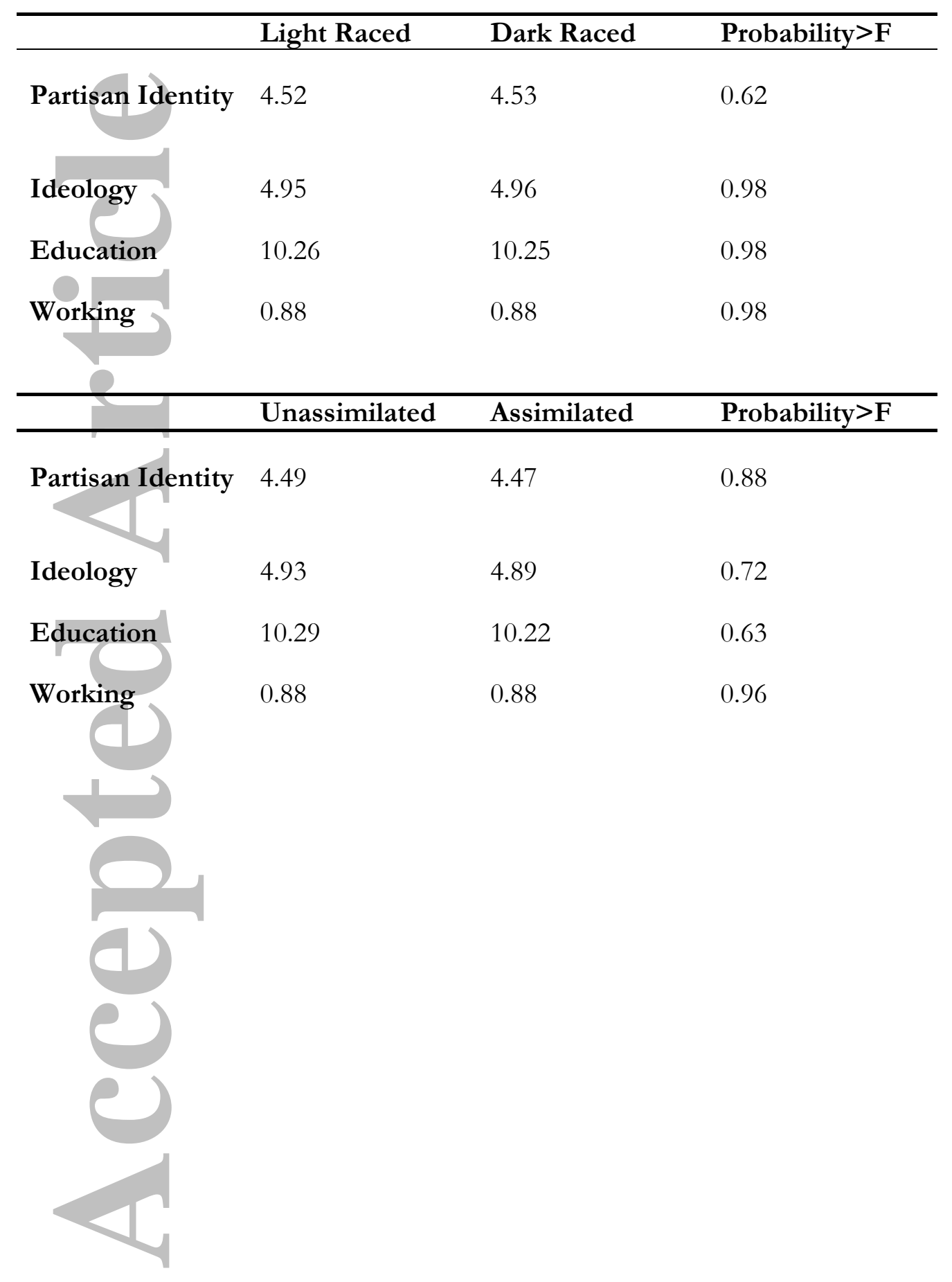




\section{ONLINE APPENDIX 7: VIGNETTE, EXPERIMENT 2}

In Montgomery, Illinois, an immigrant family gets together for dinner. Beneath the apparent cheer of the family's conversation is anxiety surrounding the aggressive lobbying by local advocates for stricter immigration laws. The most severe proposal would deport all immigrants who did not initially enter the country legally - regardless of reason - to return to their native countries and reapply for admission. For the Lina family, this would mean returning to the persecution of a military dictatorship.

With the overwhelming sense of powerlessness that often accompanies being an immigrant, the Linas have resolved to continue working hard and enjoy any remaining time they have in the United States.
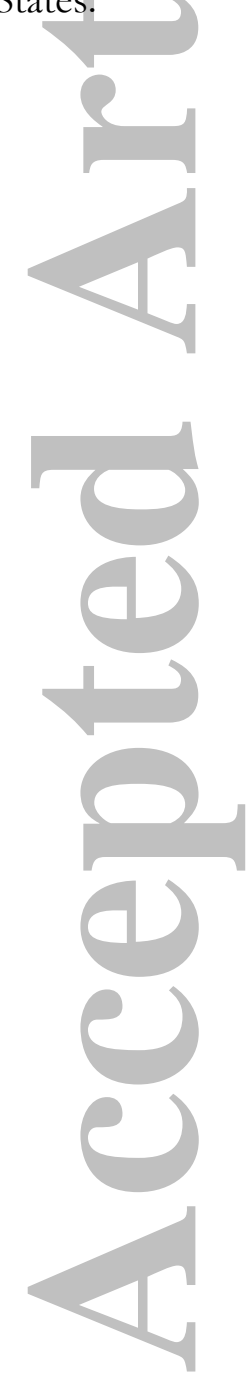
ONLINE APPENDIX 8: PHOTOS, EXPERMIENT 2

Dark Raced Condition*

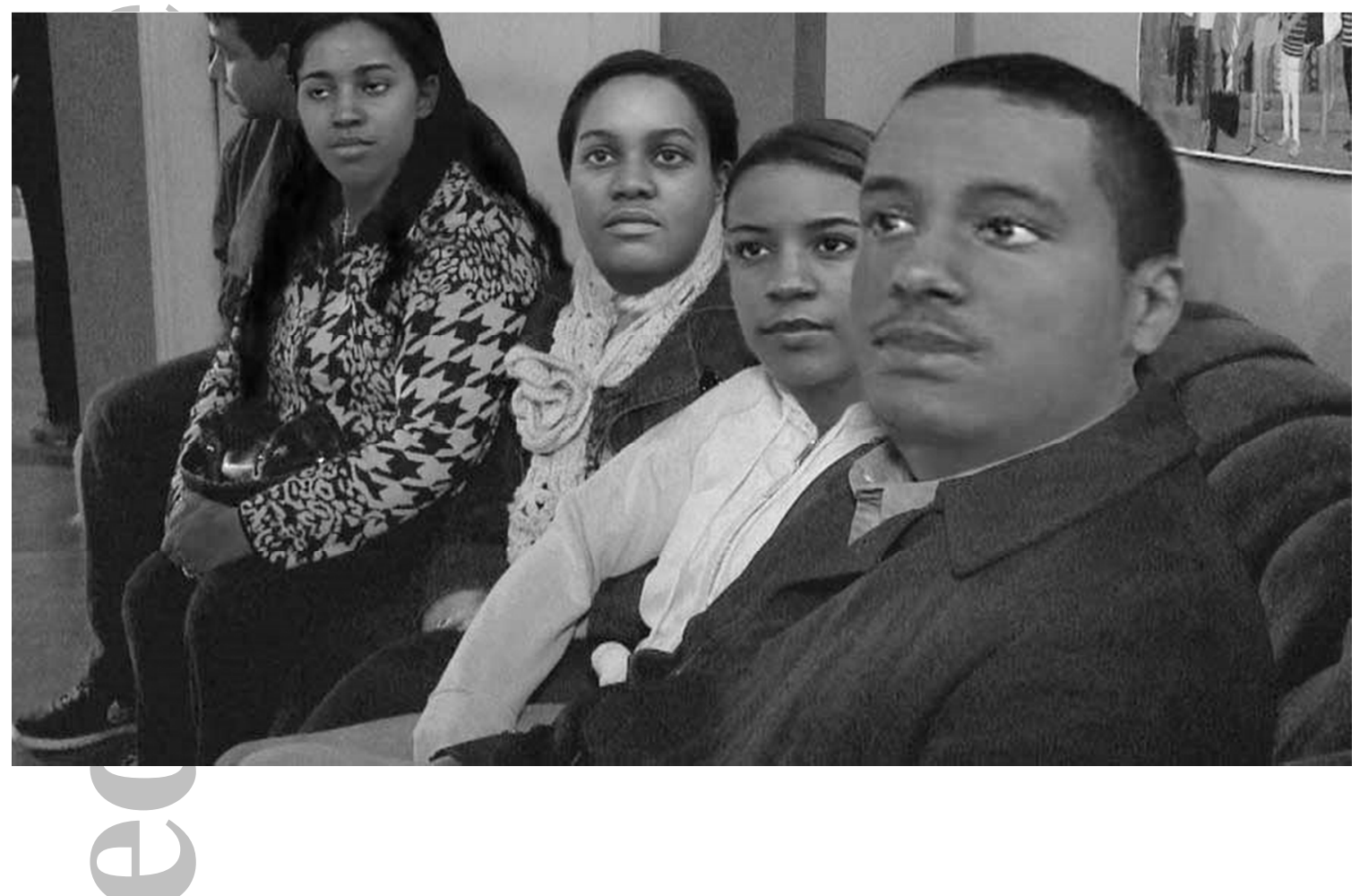

Light Raced Condition*

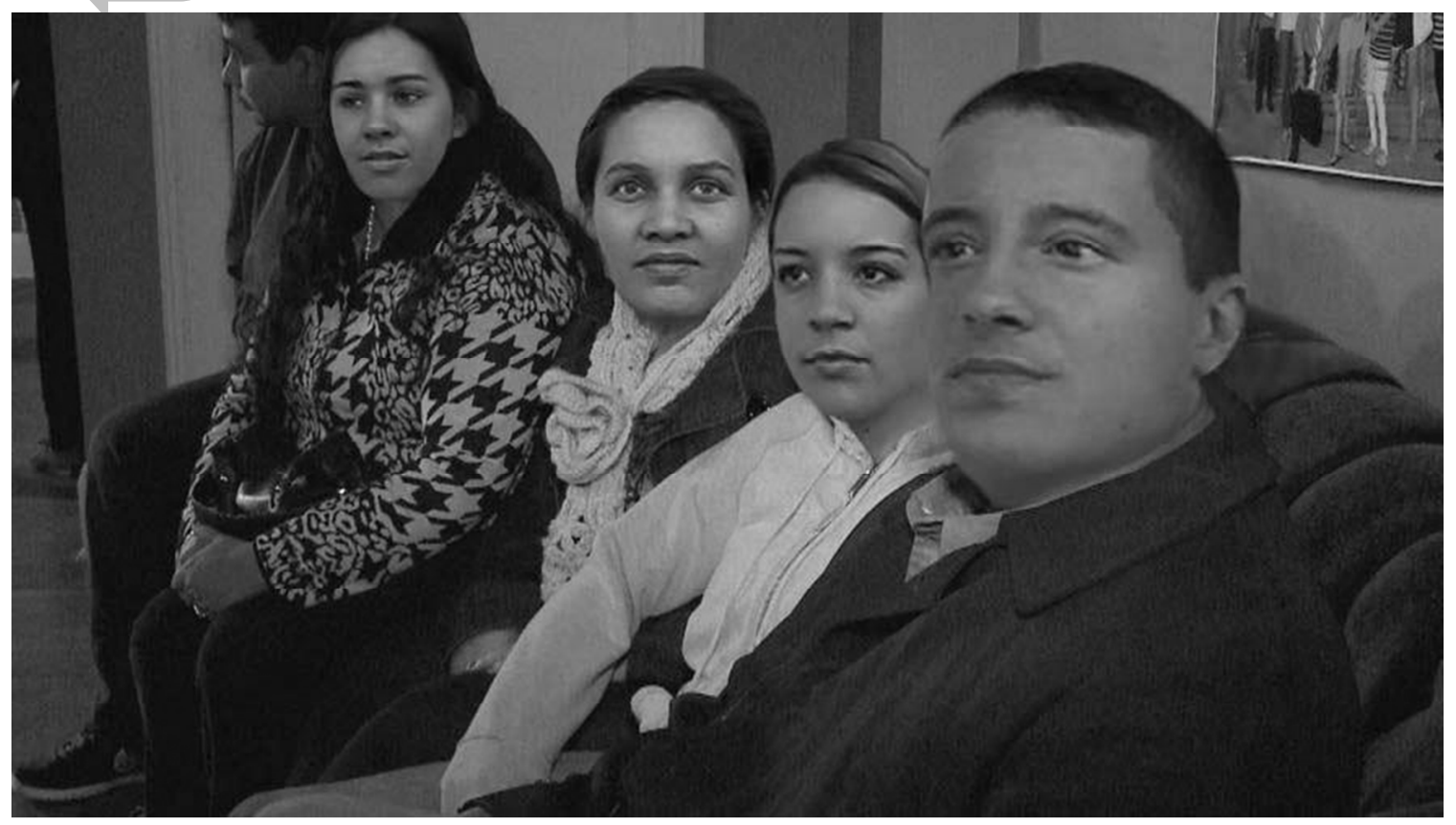

*Note: Original photos used in experiment were in full color. 
ONLINE APPENDIX 9: PERCEIVED COUNTRY OF ORIGIN BY TREATMENT, EXPERIMENT 2

\begin{tabular}{lcc}
\hline & Light Skin & Dark Skin \\
\hline Africa & $1.8 \%$ & $31.1 \%$ \\
Eastern Europe & $14.9 \%$ & $4.9 \%$ \\
$\begin{array}{l}\text { Latin America } \\
\begin{array}{l}\text { Western } \\
\text { Europe }\end{array}\end{array}$ & $79.5 \%$ & $58.9 \%$ \\
Southeast Asia & $2.0 \%$ & $1.3 \%$ \\
Australia & $1.8 \%$ & $3.8 \%$ \\
\hline TOTAL & $0.0 \%$ & $0.0 \%$ \\
\hline
\end{tabular}

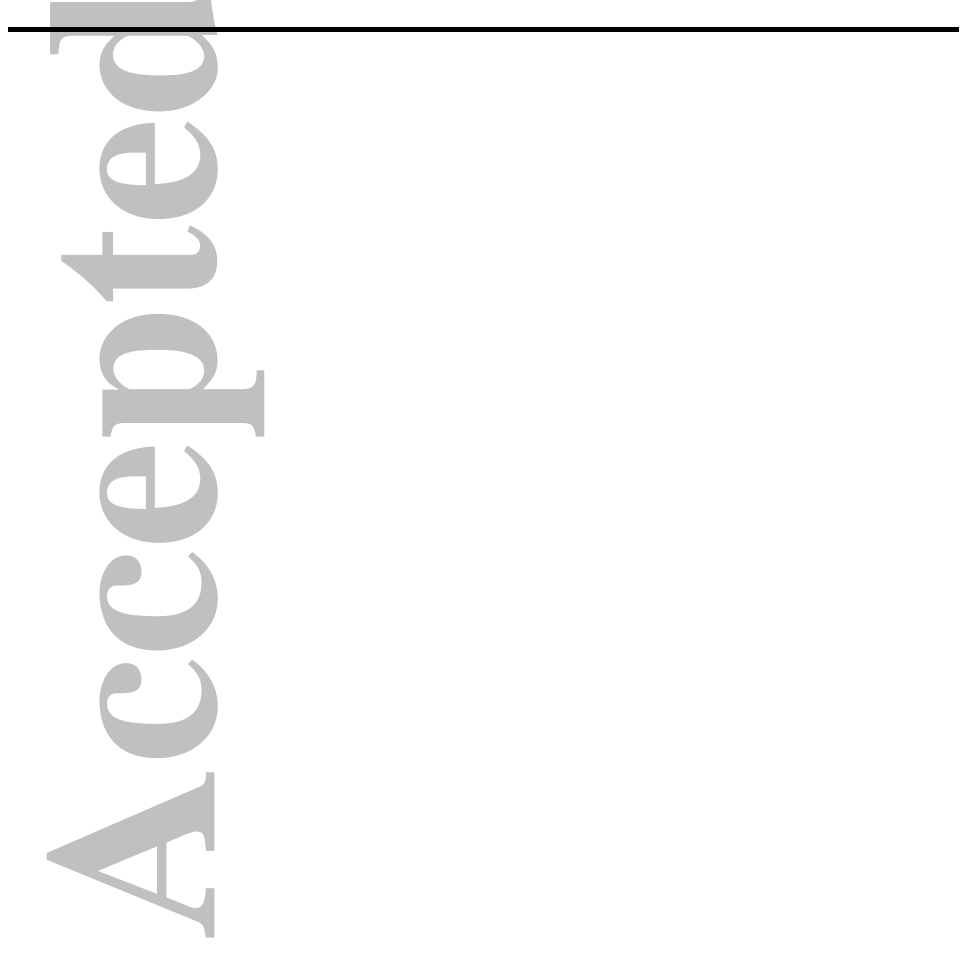




\section{ONLINE APPENDIX 10: BALANCE CHECKS, EXPERIMENT 2}

\begin{tabular}{llll}
\hline & Light Raced & Dark Raced & Probability $>$ F \\
\hline Partisan Identity & 3.34 & 3.47 & 0.09 \\
Ideology & 4.54 & 4.83 & 0.00 \\
Working & 3.33 & 3.33 & 0.96 \\
& 0.79 & 0.79 & \\
\hline
\end{tabular}

